\section{Commentary: Endoscopic resection versus surgery for superficial esophageal cancer: Ageless or timeless?}

\author{
Jules Lin, MD
}

In this issue of the Journal, Raman and colleagues ${ }^{1}$ report that endoscopic resection (ER) is an alternative in patients with cT1a esophageal cancer at low risk of nodal involvement with similar survival compared with surgery regardless of age. This manuscript is timely, with many patients with T1a tumors being treated with ER. However, due to limitations in the National Cancer Database (NCDB), important data points are missing from the analysis, making the results more difficult to interpret.

The main concern is that several factors associated with increased nodal disease with T1a tumors could not be controlled for, with missing data on lymphovascular invasion, tumor size, and tumor grade in almost $50 \%$ of patients undergoing ER. ${ }^{2}$ Some patients likely underwent esophagectomy due to these risk factors, and in a similar NCDB study looking at ER versus surgery, the rate of lymphovascular invasion was greater in the esophagectomy group. ${ }^{3}$ Identifying the subgroup of patients who may benefit from initial esophagectomy may be important, since Plum and colleagues ${ }^{4}$ reported inferior disease-free survival in patients who underwent surgery following failed ER compared with a primary surgery group. Data were also unavailable for cancer-specific or recurrence-free survival and regional and distant metastatic recurrence rates.

Although patients were included based on clinical staging, endoscopic ultrasound is only $82 \%$ sensitive and $91 \%$ specific, and some patients with cT1a actually have more advanced disease. Unfortunately, pathologic $\mathrm{T}$ stage was missing in $45 \%$ of patients undergoing ER, and after esophagectomy, pathologic $\mathrm{T}$ stage was upstaged in $20 \%$

\footnotetext{
From the Section of Thoracic Surgery, Department of Surgery, University of Michigan Medical Center, Ann Arbor, Mich.

Disclosures: Author has nothing to disclose with regard to commercial support.

Received for publication Dec 8, 2019; revisions received Dec 8, 2019; accepted for publication Dec 8, 2019; available ahead of print Jan 7, 2020.

Address for reprints: Jules Lin, MD, Section of Thoracic Surgery, 1500 E. Medical Center Dr, 2120TC/5344, Ann Arbor, MI 48109-5344 (E-mail: juleslin@umich. edu).

J Thorac Cardiovasc Surg 2020;160:303-4

$0022-5223 / \$ 36.00$

Copyright (C) 2020 by The American Association for Thoracic Surgery

https://doi.org/10.1016/j.jtcvs.2019.12.039
}

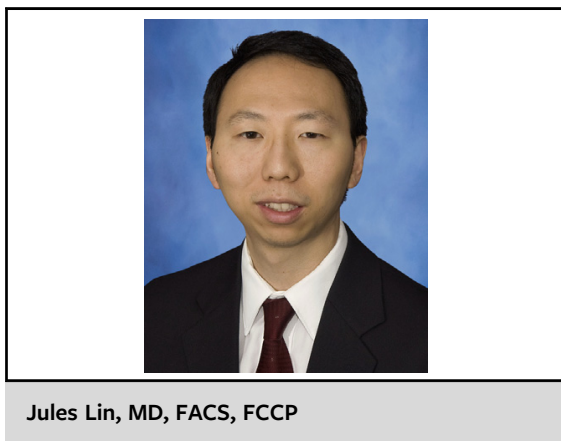

\begin{abstract}
CENTRAL MESSAGE
Endoscopic resection is an option across all ages for T1a cancer, but esophagectomy remains important in patients with a greater risk of nodal disease.
\end{abstract}

(78/383) of patients. It would be better to include only patients with pathologic T1a tumors. In addition, the rate of nodal disease in the esophagectomy group was $9 \%$ to $10 \%$ with a 4 -fold increase in risk of adjusted mortality. Patients found to have nodal disease intraoperatively and treated with adjuvant therapy are the most likely to have a survival benefit from esophagectomy, and whether these patients have improved survival compared with patients undergoing ER diagnosed with nodal disease during follow-up surveillance needs to be determined.

Marino and colleagues ${ }^{3}$ evaluated ER versus surgery in a similar NCDB study and found that ER was associated with decreased 90-day mortality. However, in patients surviving longer than 90 days, esophagectomy was associated with better overall survival. Although esophagectomy has a greater perioperative mortality, patients who survive the perioperative period may derive benefit from a nodal dissection, especially those at greater risk for nodal metastases. In the current study, although not statistically significant, 90-day mortality was greater after esophagectomy ( $4 \%-7 \%$ vs $1 \%$ ).

Although the current study suggests that ER is ageless and is an option for patients with T1a and a low risk of nodal involvement across all ages, in patients at greater risk for nodal disease, especially as endoscopic resection is being evaluated for submucosal T1b tumors with up to a $20 \%$ risk of nodal disease, it is important to remember that esophagectomy can be curative, safely performed in carefully selected patients by experienced thoracic surgeons, 
and remains an important option and the timeless gold standard.

\section{References}

1. Raman V, Jawitz OK, Voigt SL, Yang CJ, Harpole DH, D'Amico TA, et al. The effect of age on survival after endoscopic resection versus surgery for T1a esophageal cancer. J Thorac Cardiovasc Surg. 2020;160: 295-302.e3.
2. Weksler B, Kennedy KF, Sullivan JL. Using the National Cancer Database to create a scoring system that identifies patients with early-stage esophageal cancer at risk for nodal metastases. J Thorac Cardiovasc Surg. 2017;154:1787-93.

3. Marino KA, Sullivan JL, Weksler B. Esophagectomy versus endoscopic resection for patients with early-stage esophageal adenocarcinoma: a National Cancer Database propensity-matched study. J Thorac Cardiovasc Surg. 2018;155:2211-8.e1.

4. Plum PS, Hölscher AH, Pacheco Godoy K, Schmidt H, Berlth F, Chon SH, et al. Prognosis of patients with superficial T1 esophageal cancer who underwent (endoscopic resection before esophagectomy - a propensity score-matched comparison. Surg Endosc. 2018;32:3972-80.
See Article page 295.

\section{Commentary: Age is just a number: Let's give endoscopy a chance in the treatment of early esophageal cancer}

\author{
Jesse Rappaport, MD, and Siva Raja, MD, PhD
}

As the expertise in complex interventional endoscopic therapies increases, the need for traditional esophagectomy for cT1a esophageal cancer as the treatment of choice has been increasingly called into question. Esophagectomy as an operation is almost universally considered a life-altering operation despite significant improvements in minimally invasive surgical options and markedly decreased mortality compared with the past. The radical aspect of this operation was and is justified by the aggressive biology of the disease process. However, recent works have shown the premalignant condition of Barrett's esophagus can be eradicated with radiofrequency ablation, ${ }^{1}$ and the biology of mucosal esophageal cancer is often relatively indolent with low rates of lymph node metastasis. ${ }^{2}$ These are the rationale that have driven the field to adopt organ-preserving options such as endoscopic resections in the place of esophagectomy for these early cancers.

In their article, Raman and colleagues ${ }^{3}$ sought to evaluate the effect of age on survival in the growing use of

From the Department of Thoracic and Cardiovascular Surgery, Heart and Vascular Institute, Cleveland Clinic, Cleveland, Ohio

Disclosures: Authors have nothing to disclose with regard to commercial support.

Received for publication Dec 13, 2019; revisions received Dec 13, 2019; accepted for publication Dec 16, 2019; available ahead of print Jan 7, 2020.

Address for reprints: Siva Raja, MD, PhD, 9500 Euclid Ave, J4-1, Cleveland, OH 44195 (E-mail: rajas@ccf.org).

J Thorac Cardiovasc Surg 2020;160:304-5

$0022-5223 / \$ 36.00$

Copyright (c) 2020 by The American Association for Thoracic Surgery

https://doi.org/10.1016/j.jtcvs.2019.12.046
Check for updates

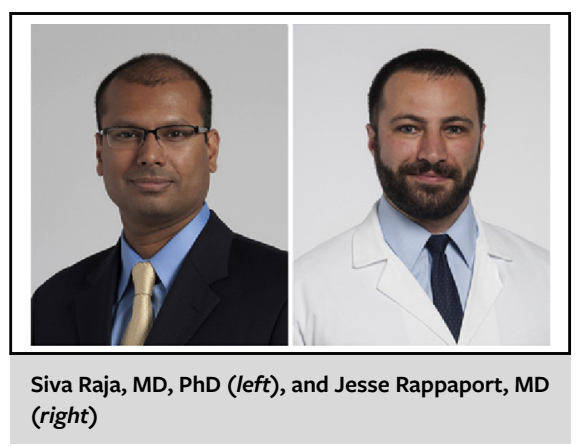

CENTRAL MESSAGE

Endoscopic resection for very early esophageal cancer may be the right first-line choice for all patients, especially elderly patients, who may be at greater risk for conventional surgery.

endoscopic resection compared with esophagectomy for clinical T1a carcinoma. In their retrospective review of the National Cancer Database, they found that survival was comparable between the 2 treatments across all age groups. Their study took on the hurdles of incomplete data in the National Cancer Database through propensity score-matched patients and a "high-risk" subset, which demonstrated similar results in overall survival for both treatment options. The trends toward greater 90-day mortality with esophagectomy could not statistically be confirmed based on their patient subset, likely limited by too few numbers, but has been noted by others. ${ }^{4}$

There is no doubt that the work by Raman and colleagues ${ }^{3}$ adds to the literature that suggests that endoscopic therapy for T1a cancer is both safe and effective, albeit the database lacks the granularity to determine what that "endoscopic resection" may actually be. Even within this very 